\title{
HISTORIA Y MEMORIA DE LAS MUJERES ASEDIADAS ${ }^{1}$
}

Elena Fernández García

Universidad Autónoma de Barcelona

elena.fernandez@uab.cat

Recibido: 23-02-2011

Aceptado: 23-03-2011

Resumen: El presente artículo se propone constatar la implicación femenina en los escenarios de la lucha, concretamente en episodios de verdadera amenaza como en el caso de los sitios, e intentar determinar hasta qué punto la necesidad de tomar partido en la defensa de sus ciudades, de sus familias, significó una mayor o menor ocupación de espacios propiamente masculinos por parte de ellas. Específicamente, se tratará de recuperar del olvido la acción femenina y su contribución en tres episodios bélicos de importancia como son la sublevación catalana de la Guerra dels Segadors, la Guerra de Sucesión y la Guerra de la Independencia. Tres ejemplos de conflicto en los que destaca sobremanera la acción de las mujeres asediadas.

Palabras Clave: Mujeres, sitios, Guerra de la Independencia, Guerra dels Segadors, Guerra de Sucesión.

\begin{abstract}
This article was proposed to verify the involvement of women in the fight scenes, particularly in episodes of real threat as in the case of sieges, and to try determining to what extent the need to take a stand in defense of their cities, their families, meant a greater or lesser occupation of properly masculine spaces by them. Specifically, we try to retrieve from oblivion the women action and their contribution on three major military events such as the Catalan uprising known as Reapers' War, the War of Spanish Succession and the Peninsular War. Three examples of conflicts in which the action of women under siege tales special importance.
\end{abstract}

Keywords: Women, sieges, Reapers' War, War of Succession, Peninsular War.

\footnotetext{
${ }^{1}$ Algunas de las ideas introducidas en el presente artículo son el resultado del proyecto de investigación La internacionalització de la perspectiva de gènere dins el període de la guerra de Successió. Subvencionado por el Centre d'Història Contemporània de Catalunya (2009-00456).
} 


\section{Introducción}

A menudo la historiografía militar dedicada a la guerra ha descuidado la contribución femenina. En el mejor de los casos, se ha tratado la presencia de las mujeres en el frente de forma anecdótica y se ha presentado como un apéndice añadido a las otras secciones de los estudios marcados por el elemento masculino, dedicados a la historia política, económica o social. Esta circunstancia no debe extrañarnos, pues toda actuación relacionada con las armas ha estado unida al mundo de la política y, por tanto, se ha venido desarrollando en los espacios públicos. Si tenemos en cuenta que lo público, según la tradicional asignación patriarcal de los espacios, no pertenecía a las mujeres, inevitablemente la guerra se convertía en un territorio vedado para el sexo femenino. Al mismo tiempo, siguiendo estos planteamientos patriarcales, la supuesta constitución y fragilidad física de las mujeres no las hacían adecuadas para los enfrentamientos bélicos. Únicamente era a los hombres a los que se les encomendaba la misión de la lucha. Estos han sido sin duda los principales argumentos esgrimidos por la historiografía tradicional para obviar el papel femenino en cualquier conflicto bélico. No obstante, actualmente las evidencias históricas y la amplia bibliografía dedicada al tema de la mujer y la guerra nos permiten afirmar que las mujeres han desarrollado un papel activo, y no meramente excepcional, tanto en el contexto bélico como en el campo de batalla a lo largo de la historia.

No entraré a valorar cuáles han podido ser las circunstancias que han llevado a las mujeres de diferentes épocas y lugares a tomar parte en los conflictos. Mientras algunas lo hicieron por voluntad propia, empujadas por la defensa de un ideal o proyecto político concreto, posiblemente otras se vieron inducidas a la lucha por su propia protección o la de sus seres queridos. El presente artículo se propone, pues, ofrecer algunos ejemplos de intervención femenina que plasman una implicación activa en episodios de verdadera amenaza y de innegable riesgo como en el caso de los asedios. Mi intención únicamente es constatar la presencia femenina en los escenarios de la lucha e intentar determinar hasta qué punto la necesidad de tomar partido en la defensa de sus ciudades, de sus familias, significó una mayor o menor ocupación de espacios propiamente masculinos por parte de ellas. Específicamente, se tratará de recuperar del olvido la acción femenina y su contribución en tres episodios bélicos de importancia como son la sublevación catalana de la Guerra dels Segadors, la Guerra de Sucesión y la Guerra de la Independencia. Tres ejemplos de conflicto en los que destaca sobremanera la acción de las mujeres asediadas. 


\section{Las mujeres en la Guerra}

Es un hecho casi incuestionable que, de una u otra manera, la población civil, y en concreto el sexo femenino, siempre se han visto damnificados por los trastornos de la guerra y la violencia ejercida por las tropas más allá de los campos de batalla. Las razones de este fenómeno son varias, aunque podemos destacar dos. En primer lugar, la progresiva profesionalización de los ejércitos iniciada en la época moderna no vino acompañada de un distanciamiento entre los campos de batalla y los núcleos urbanos, de manera que las habituales carencias sanitarias o de abastecimiento de la soldadesca continuaron recayendo sobre los habitantes de las poblaciones inmediatas a la lucha. Como consecuencia de su nueva condición profesional, los ejércitos modernos tenderán a crecer. Pero el aumento en el volumen de soldados no irá acompañado de una mejora en la organización interna de las tropas, lo que provocará que la población se vea impelida a tener que suplir con su sacrificio las necesidades de los destacamentos militares (Black, 1991). Y, en segundo lugar, a causa de la mejora en las estrategias defensivas y ofensivas de estos nuevos ejércitos, la guerra se irá haciendo cada vez más estática (Paret, 1991). La toma de una plaza o el avance del frente serán más lentos y costosos, constriñendo a las ciudades y a sus habitantes a largos sitios (Espino, 2001). Dicho de otro modo, la lucha no queda restringida al campo de batalla, sino que en muchos casos se traslada a las localidades más próximas o de una relevancia estratégica considerable, convirtiendo el suelo urbano en una extensión más del terreno de lucha. Por consiguiente, aunque teóricamente la guerra se despliega en los espacios públicos, en un contexto armado los límites de estos espacios acaban por rebasar las fronteras de lo privado. De manera que no cabe duda de que la guerra, emblema de la esfera pública, termina repercutiendo también en lo doméstico - espacio reservado para las mujeresadoptando las formas de toda clase de abusos (Anderson, 1990) y poniendo de manifiesto actuaciones femeninas del todo ajenas al ideario patriarcal masculino. Unas acciones que, como se verá, demuestran que la tradicional afirmación de que las mujeres no "hacen la guerra" es tan sólo un espejismo provocado por el hecho de que en el pasado los soldados siempre han sido hombres. Por el contrario la realidad de los hechos evidencia que el trabajo y la colaboración de las mujeres en las campañas militares siempre han existido y han resultado definitivos (Nash y Tavera, 2003).

Desde la Antigüedad, y en concreto en la cultura grecolatina, el papel de la mujer en las guerras estuvo bastante acotado. En términos estrictamente bélicos únicamente se reclamó de las mujeres su aportación como madres de los futuros 
soldados, rechazando así cualquier contribución que fuese más allá de este rol maternal. Incluso, a pesar de la existencia de diosas de la guerra como Atenea o Minerva, la participación femenina en el combate era vista como un claro signo de incivilidad. Figuras como las amazonas son un claro ejemplo. Representadas por la mitología como un pueblo formado por guerreras andróginas y violentas, protagonizan leyendas cuyo objetivo principal era resaltar su barbarismo y demostrar la peligrosidad de permitir la desnaturalización de la feminidad consintiendo a las mujeres el uso de las armas. Estas narraciones míticas ponen de relieve que, pese a no tener una motivación propiamente militar, ya en la antigüedad se intentó por todos los medios apartar a sus matronas de los frentes y evitar la asistencia de mujeres a los campamentos militares. Esto no se logró (Palao, 2005).

Entre las mujeres que tradicionalmente formaban parte del séquito que acompañaba a las tropas encontramos desde cantineras o soldaderas, hasta aquellas que, emparentadas con algún soldado, decidían seguirles en el frente. Las primeras, mujeres de honorabilidad dudosa, habían abandonado su casa para seguir a las tropas y mantenían relaciones de cierta camaradería con los soldados. Nada que ver con la actitud de aquellas mujeres que, ante la falta de patrimonio o la imposibilidad de permanecer en el domicilio familiar, acompañaban a sus amantes, maridos, hijos o hermanos al campo de batalla. Concretamente, en la Guerra de la Independencia son muy comunes las alusiones a enamoramientos entre soldados extranjeros y españolas que renunciaron a sus hogares. Esas mujeres, entonces, decidían integrarse en el conjunto de las tropas de sus amantes (Birks, 2007: 24-25 y Hathaway, 1997: 250-251). Este fue el caso de Juana María de los Dolores de León, la esposa de sir Harry Smith, a quien conoció tras el sitio de Badajoz y al que acompañó durante el resto de la campaña peninsular (Moore Smith, 1902). Estas mujeres compartieron las penalidades de la tropa experimentando el rigor de la marcha o las enfermedades en los campamentos. En la memoria de los soldados británicos quedaron grabadas, por ejemplo, las duras escenas de mujeres y niños muertos de frío durante la penosa retirada de la campaña de La Coruña de 1809 (Schaummann, 1999).

En cierta manera la presencia de todas ellas se toleraba e incluso era vista como conveniente por los altos mandos, pues el papel económico y asistencial que cumplían resultaba fundamental para el mantenimiento de las guarniciones. Ellas eran las encargadas del cuidado de los soldados, ocupándose de la cocina o la costura, auxiliando a los enfermos y heridos, o respondiendo a las necesidades sexuales de la tropa, evitando así el estallido de sucesos violentos contra la población femenina del lugar. 
Sin embargo, a pesar de ser un elemento clave para la sostenibilidad de las guarniciones, las prohibiciones y restricciones sobre la presencia femenina entre la tropa existían. Por ejemplo, las regulaciones internas del ejército inglés únicamente permitían que cada compañía fuese acompañada por seis esposas de soldados (Brett-James, 1972). En la mayoría de los casos las autoridades militares se opondrán a la existencia de mujeres entre la soldadesca, argumentando que la existencia de soldaderas minaba la concentración de las tropas y daba pie a modos de conductas inmorales entre los soldados. Incluso se las acusaba de ser un estorbo que dificultaba la movilidad y la logística de los ejércitos (Bowen, 2004). En esta línea, estudios como los de Peter H. Wilson (1996), para el caso alemán, confirman un progresivo declive de la presencia femenina entre las tropas a partir de la segunda mitad del siglo XVII como consecuencia de las nuevas directrices morales que acompañaron a la Reforma y la a Contrarreforma y que promovieron un paulatino confinamiento de las mujeres en roles de género cada vez más restrictivos y acotados. Igualmente interesantes son las aportaciones de John A. Lynn (2008) sobre el tema, pues coincide con Wilson en la afirmación de que la importancia del papel de la mujer que seguía a los ejércitos empieza a diluirse a finales del siglo XVII.

No obstante, y sin negar que la Reforma y Contrarreforma católica precipitaran el cambio, las evidencias presentadas por otros historiadores advierten que no será hasta las Guerras Napoleónicas (1792-1815) cuando las mujeres serán expulsadas oficialmente de los ejércitos y relegadas definitivamente a un mero papel reproductivo (Applewhite y Levy, 1993; Arbor, 1992) . Los cambios introducidos por la Ilustración en los roles de género, sumados a una nueva concepción "nacional" de los conflictos, provocará que a partir de entonces sólo los hombres sean vistos como los "protectores de la nación", dejando para las mujeres únicamente la custodia del hogar y prohibiendo explícitamente su presencia junto a la tropa. Esta incipiente idea irá extendiéndose de forma gradual a lo largo de toda Europa. De manera que durante el siglo XIX la mayoría de países seguirán el modelo militar francés y prusiano y también introducirán medidas para reducir el número de asistentes femeninas en los ejércitos.

Pero, pese a las instrucciones contrarias a la presencia femenina en las filas militares y las restricciones a la participación de las mujeres en los conflictos bélicos, lo cierto es que las guerras, debido a una ampliación territorial más allá del campo de batalla, acabaron por entrar de lleno en los núcleos urbanos obligando a sus habitantes y entre ellos las mujeres- a tomar parte en la lucha. Así pues, encontramos a otras mujeres que, sin acompañar a las tropas, se veían inmersas en la guerra como consecuencia del asedio de sus ciudades. Paradójicamente, pese a ser sujetos pasivos de 
la situación bélica en la que muchas de ellas se vieron involucradas, su papel en las defensas de sus poblaciones fue muy activo. Sus actuaciones fueron más allá de las habituales labores de intendencia o sanidad. Era frecuente verlas colaborar en la reparación de fortificaciones o incluso interviniendo enérgicamente en las acciones defensivas llevadas a cabo por los vecinos asediados. En este sentido, pese al persistente tabú de los roles de género, hubo mujeres que protagonizaron actuaciones bélicas puntuales o que accedieron voluntariamente o por necesidad a colaborar con los ejércitos en el fragor de la batalla, poniendo de este modo en entredicho la idea de que la guerra era un tema propiamente de hombres.

\section{Los hechos: mujeres en pie de Guerra}

No cabe duda de que la guerra altera el correcto funcionamiento de los papeles de género. La correlación público-masculino/doméstico-femenino, que tanto se promulgó durante el siglo XVIII, se ha mostrado claramente carente de sentido en cada uno de los conflictos bélicos a lo largo de la historia. Así pues, la tradicional división de tareas por sexos en un contexto de guerra ha sido constantemente contravenida. La manifestación más sintomática de esta transgresión de las directrices patriarcales es la toma de armas por parte de las mujeres en épocas de guerra. De tal forma que en los períodos de lucha el ejercicio de las armas deja de ser una cuestión exclusivamente masculina (Cook, 2006). Este hecho está sólidamente sustentado por infinidad de testimonios (Prichard, 1854; Carter, 1860; Clayton, 1879; Menie, 1893) obras literarias y artísticas (Wheelwright, 1989) e incluso folklore (Dugaw, 1989), donde aparecen doncellas guerreras, heroínas y mujeres que, disfrazadas de hombres y ocultando su identidad, lucharon junto a sus compañeros masculinos (Dekker y Van de Pol, 1989; Stepto, 1996). Es más, cuando la necesidad así lo requería, las mujeres colaboraban en aquello que hiciera falta, dejando a un lado consideraciones y mentalidades arcaicas nada acordes con una situación bélica. Incluso, en circunstancias de verdadero riesgo, serán las propias esferas de poder las que, a pesar de las normas patriarcales, apoyarán la intervención de las mujeres en el desarrollo de tareas defensivas.

El escenario acostumbraba a ser siempre el mismo: una población sitiada en la que los defensores necesitaban toda la ayuda que pudieran recibir, en especial en labores complementarias como el de cuidado de los soldados, y un ir y venir de mujeres cargadas con munición, alimentos o agua. Al mismo tiempo, había ocasiones en que se 
iba más allá de estas tareas de apoyo y se traspasaban los límites asignados al sexo femenino. De modo que, como veremos, es posible encontrar testimonios que certifican la intervención más activa en la defensa de las murallas o de alguna plaza por parte de estas mujeres (Salmonson, 1991). Por lo general estos episodios acaban con éxito y dan lugar a exaltaciones públicas, enalteciendo el valor de las protagonistas, y muestras oficiales de agradecimiento hacia estas heroínas por su contribución en la salvaguarda de la ciudad o la villa. La realidad es que en estos momentos, en los que las mujeres se verán impelidas a tomar las armas, la percepción de transgresión de los roles asignados al sexo femenino y los posibles conflictos ideológicos al respecto se verán diluidos ante la necesidad de supervivencia.

\subsection{Las mujeres sitiadas en la Guerra del Segadors (1640-1652) y la Guerra de Sucesión (1701-1715)}

Por ejemplo, son múltiples los testimonios y documentos que advierten de la participación femenina en la sublevación catalana de 1640-1650. Conocido es el valor de las mujeres de Barcelona ante el ataque del ejército realista del marqués de Los Vélez el 26 de enero de 1641:

"Pujaren á la montanya de Montjuich, unes per donar refresch als que batallaven, altres
per portar pólvora, bales, draps y tot lo accessori pels pedrenyals, altres a falta de draps
donaven las robes que portaven, unes ab pica y altres ab arcabus y predrenyals
guerrejaven ab valentia, y açó que havia manat pel pregoner que les dones no sortissen
de llurs cases, sota pena de cent açots. Pero elles conegueren que la necessitat las
disculpaba de semblant manament $[. .$.$] Vegeren les dones que no tenia lloch la lley, y$
com que tampoch la tenia son pit, y son cos les arrastrava a que pugessen la montanya,
axis ho feren, donant lloch á que, quan escriga llargament aquesta victoria las alaben"
(Font, 1897: 21).

En este fragmento se muestra claramente cómo oficialmente estaba vedada a las barcelonesas la participación directa en la contienda, bajo pena de castigo; dejando manifiesto cuál era el proceder habitual de la época: las mujeres no debían involucrarse en la lucha porque no era una cuestión de su incumbencia. Ellas debían ocuparse de los asuntos de índole doméstica. Pero este texto también pone de relieve la laxitud con la que las catalanas observaban ese imperativo. Una laxitud que otrora hubiese sido censurada, pero que en un contexto bélico se ensalza y se alaba. Otro aspecto a destacar de este testimonio es el estilo narrativo que domina este fragmento y que denota el tono de leyenda que poco a poco fue adquiriendo la defensa de la ciudad de Barcelona. Apelando al patriotismo, los sucesos son presentados bajo una forma épica quizás con la 
intención de levantar los ánimos de toda la población e incitar a que plantara cara a las tropas hispánicas. En esta línea el testimonio de los jesuitas es aún más impresionante:

\begin{abstract}
"Y si quisiéramos poner la tercera causa de esta victoria, ha de ser los religiosos y mujeres, porque aquellas, ó por traer las conciencias más ajustadas, temían menos el riesgo y peleaban con más valor, ó por entender mejor la justa causa de la defensa de la patria, trataban más de defenderla, no exceptuando á ninguna de las armas y ejercicio militar [...] Pues las mujeres no es creíble el ánimo y valor que mostraban, unas con las armas, otras suministrando lo necesario para la guerra y regalo de los soldados, a quien ellas regalaban no solamente de palabra, sinó con la obra, no exceptuándose de este valeroso ejercicio, ni aun la más noble é ilustre, y finalmente, andaban así ellas como ellos tan encarnizadas con la sangre castellana, que no se contentaban con derramarle cuanto podían, sino que cada cual pretendía traer recuerdo y memoria de los que dejaban muertos, y en las espadas traían espetadas, cuál las orejas, cual las narices, cual las lenguas castellanas [...]" (Memorial Histórico Español, 1862: 142-143).
\end{abstract}

Es decir, las catalanas ante el ataque indiscriminado de las murallas de su ciudad se implicaron profundamente en su defensa, realizando tareas que iban desde el suministro y atención a los heridos hasta, llegado el caso, ocupar el lugar de aquellos que habían caído en la batalla. Entonces, de acuerdo con este texto, parece que las barcelonesas inicialmente estaban destinadas a ser una especie de segunda línea o línea de apoyo a los combatientes masculinos, pero evidentemente ante el desconcierto de la lucha y la necesidad de mantener las defensas de su ciudad se vieron obligadas a llevar a cabo otras misiones para las que en un primer momento no se contaba con ellas. Lo mismo ocurrió en Tortosa (abril de 1641), Tarragona (julio-septiembre de 1643) o Lleida (mayo de 1647) asedios en los que las mujeres también sobresalieron no sólo por sus labores de apoyo sino también por sus intervenciones ofensivas.

Igualmente destacada es la participación de las catalanas en la Guerra de Sucesión (1701-1715). Particularmente, notable es su actuación durante el asedio de Barcelona de 1706 por parte de las tropas borbónicas. Tan lucido fue el servicio de las mujeres en la defensa que encontramos referencias a su protagonismo en varias crónicas e incluso en un opúsculo titulado Proesas que las barcelonesas donas han ostentat en este siti del any 1706. Según revelan dichos documentos, las mujeres se movilizaron al grito de "a les armes, a les armes, germans, que desemparen Montjüic" ante la noticia de la posible pérdida de la fortaleza a manos de las fuerzas borbónicas. En palabras de Feliu de la Peña "fuè prodigioso el valor de las mugeres, pues con valiente desprecio del riesgo, llevavan refresco á los que peleavan, y municiones...como los mejores Soldados" (De la Peña, 1709: 557). Asimismo, las Narraciones Históricas de Francesc Castellví al tratar el tema del asedio de Barcelona confirmarán el despliegue femenino: 
"Acudieron toda clase de gentes: muchos dejando sus cuerpos, mujeres y niños en gran número, a subir agua y pertrechos; otras subían acomodadas viandas, dándolas de balde a soldados y paisanos; corrían entre los más expuestos riesgos y no pocas con armas. En breve espacio condujeron todos los aprestos necesarios al castillo y al caer la noche en la gran cisterna sólo faltaba palmo y medio de agua, Las mismas mujeres transportaban los heridos, llevaban vendas y paños para curarles y animaban al combate a todos. Sus gritos alentaban a los hombres a despreciar los riesgos. A voces les animaban. Decíanles: gracias a Dios ha llegado el tiempo que decía san Vicente Ferrer que las mujeres llevarían calzones. Estas voces enfurecían al más alto punto el brío de los hombres" (Castellví, 1997: 86-87).

Repasando estos textos resulta curioso que la intervención femenina en la salvaguarda de Barcelona de abril de 1706 sea relatada a partir de adjetivos que subrayan su carácter masculino, a pesar de que la participación de las catalanas, en este caso, se limita a la realización de las trabajos propios de su sexo, según el reparto de papeles de la época. La utilización de este recurso no parece clara: tal vez se deba a la necesidad de subrayar la valentía de las barcelonesas, o su intención sea mostrar la unión general existente contra el enemigo o, incluso, su objetivo fuese incitar a la población a participar activamente en la lucha dejando al margen cualquier pretexto pseudoteórico o moral que pudiera hacer que tanto hombres como mujeres no saliesen a defender su localidad. Pero, pese a ese posible llamamiento, como ya queda dicho, la imagen que se nos presenta en este fragmento de la contribución femenina encaja perfectamente con el ideario patriarcal de la época. Justamente, textos como la crónica Ecos de la Berdad en siete dialogos sobre lo sucedido en el asedio de Barcelona, anyo 1706 confirman lo dicho:

“[...] Solo faltava que tambien las mugeres tomassen las armas. [...] No seria la primera vez que lo han hecho. No las tomaron, pero no fue poco lo que aÿudaron, pues subiendo muchas al tiempo que los demàs à Montjuique, reconociendo que avía en la fortaleza falta de agua, traxeronla con tanta abundancia, que bastó para refrigerar à los que peleavan, $\ddot{y}$ llenaron la cisterna, $\ddot{y}$ algunas bocas, $\ddot{y}$ eso sobre averlo de traer de un quarto de hora lexos cuesta arriba por la montaña. Otras cargando de polvora, y balas ivan àlos que peleavan, para el que necessitasse dello, no huviesse de bolver atrás à buscarlo. Y mugeres huvo que viendo a los Artilleros no tenian a mano los tacos, alargò parte de sus vestidos, para que mas presto tirassen [...] y aviendo algun herido, cargan con el, y de unos a otros va baxando, hasta tenerle en los Hospitales bien puesto en su cama" (Ecos de la Verdad..., 1706: 27-28).

Descripciones como esta insisten en presentar las acciones protagonizadas por las mujeres como prácticas estrechamente relacionadas con el cumplimiento del rol asignado a las mujeres en tanto que madres y esposas, $\mathbf{y}$ encargadas de dar y mantener 
la vida (Kaplan, 1990: 267-295; Nash, 2002).

\subsection{Las mujeres sitiadas de la Guerra de la Independencia (1808-1814)}

Del mismo modo que en los casos anteriores, la contribución femenina iniciada en la primavera de 1808 como consecuencia de la invasión napoleónica se caracteriza por un predominio de las tareas auxiliares, sobre todo en lo referente a la defensa de los sitios. La resistencia épica de ciudades como Zaragoza o Girona acabaron de conformar la leyenda que poco a poco se había ido formando dentro del bando patriótico acerca de la tenacidad y obstinación de los españoles y españolas y, en concreto, de su capacidad de rechazar cualquier intento de dominación proveniente de una fuerza extranjera. Pero, pese a estar hasta cierto punto fundamentado, no debemos dejarnos encandilar por el mito de la "España en armas", pues aunque la implicación de la población española fue generalizada, muchas personas, hombres y mujeres, no se movilizaron, ni participaron en la lucha por voluntad propia, sino que actuaron únicamente al ver interrumpida su cotidianidad cuando la guerra se aproximó a sus vidas. Sirva de referencia la defensa heroica del sitio de Zaragoza (julio-agosto de 1808/diciembre-febrero 1809). Mitificada y glorificada desde los órganos de opinión nacionales y extranjeros (Oman, 1909: 254; Knighton, 1838: 115; Tone, 1999: 263; Mills, 1811; Daniel, 1820: 61) fue la imagen de las patriotas aragonesas el fenómeno que más se desplegó:

“[...] las inalterables matronas que desnudas del sexo frágil alientan á los maridos, los acompañan en la lid, atan sus heridas y los envian por otras; muertos ellos ocupan su puesto, disparan el fusil y sirven el cañon á la vista del consorte traspasado: las bizarras doncellas que á par de amantes presentan su rostro varonil al enemigo, penetran su línea y le cierran en su campo [...]" (Elogio a los ilustres..., 1815: 15).

Sin duda la intensidad y el carácter eminentemente popular de la defensa de la capital aragonesa determina que en Zaragoza encontremos, por un lado, heroínas como Agustina de Aragón, Benita Portales, María Agustín, Juliana Larena, Casta Álvarez o Manuela Sancho, entre otras, que combatieron activamente en la contienda desarrollando actividades propias de un soldado más; y que, por otro lado, aparezcan figuras como María Rafols, Josefa de Azlor, Josefa Amar y Borbón o María de la Consolación Azlor que, pese a no intervenir militarmente en el conflicto, contribuyeron en la defensa de la ciudad cuidando a los heridos y procurando alimentos y bebidas a los combatientes. Muestra de la polivalencia de las zaragozanas es el siguiente texto: 
"Las mujeres de Zaragoza eran la envidia de todos y el ejemplo de los valientes. La principal tarea que les fue encomendada, era la de llevar víveres, socorros y municiones a los combatientes, cuidar de los heridos en los hospitales, fabricación de cartuchos, y suplir a los hombres en el combate hasta donde lo consintieran sus fuerzas" (Elogio a los ilustres..., 1815: 58).

Pero el caso de Zaragoza no fue el único que se vivió durante la Guerra de la Independencia. De forma similar, acciones de resistencia como las anteriormente descritas fueron llevadas a cabo por la Compañía de Mujeres de Santa Bárbara durante la defensa de Girona (Mayo-Diciembre de 1809) y la protección del castillo de Montjuich (Fernández, 2009). En este último la Compañía "se empleó en aliviar según su instituto, á los heridos y demás tropas" (Diario de Gerona, 8 de julio de 1809). Sirva de ejemplo el siguiente fragmento que hace referencia al ataque del comandante francés Verdier al castillo del 8 de julio de 1809:

\begin{abstract}
“[...] Al toque de la generala han acudido á dicho puesto (el castillo de Montjuic) todas las de su mando, recorriendo todos los puntos donde ha sido menester, para suministrar á los defensores de la patria los socorros necesarios de aguardiente y agua, y en el hospital, hilas, vendas y trapos á los heridos que allí conducían con sus brazos; en cuyos exercitos se han disputado todas á porfia, el heroico celo, caridad y patriotismo que las anima; singularmente $\mathrm{D}^{\mathrm{a}}$ Teresa Andry, la Escuadrista maria Mató, narcisa Bofill y $\mathrm{D}^{\mathrm{a}}$ Maria Josefa Jonama, quienes ademas de haber acudido en los puntos más críticos, despreciando la contínua lluvia de balas, bombas y granadas que alli caian, han contrinuido con su ejemplo y palabras, á excitar el espíritu y valor de la tropa y paisabage, que iban á socorrer el castillo de Montjuich" (Diario de Gerona, 11 de julio de 1809).
\end{abstract}

El patriotismo engendrado en el sitio de Zaragoza o de Girona se extendió a otras ciudades como Valencia o Tarragona. El ataque a esta última se inició el 3 de mayo de 1811 y duró un total de 56 días en los que el sufrimiento y las carencias (Moliner, 2009: 540) no evitaron que la población se comprometiera con la defensa de su ciudad. Y del mismo modo que en los otros casos, las mujeres desempeñaron un papel crucial. Concretamente la aportación femenina a las labores de defensa fue esencial en Tarragona. Por mencionar alguna de sus contribuciones, cabe decir que, además de ser las encargadas de cuidar a los heridos y de repartir alimentos y refrescos entre los milicianos, el general Juan Senén les encomendó la confección de hilas y vendajes y la preparación de cartuchos de pólvoras e incluso se habilitaron locales para que las mujeres realizaran dichas actividades. A continuación vemos unas palabras que elogian su cooperación:

Cuestiones de género: de la igualdad y la diferencia. No 6, 2011 - ISSN: 1699-597X - pp. 35-50 


\begin{abstract}
"Son tan dignas de estimación general las mujeres; pues sin reparar en el fuego, llenas de ardor extraordinario y compasivo; no cesaron de llevar agua para refrescar á nuestros guerreros en la fuerza del sol, del polvo y de las balas; retiraban en parihuelas a los heridos, dándoles agua, vino y vinagre aguado, hasta ponerlos en el hospital" (Spanish's Official Papers, 1808).
\end{abstract}

No obstante, como pone de relieve la presencia de varías heroínas, las habitantes de Tarragona no sólo contribuyeron al sostén de sus compañeros combatientes, sino que además se presentaron directamente en el frente. Por ejemplo, el 18 de mayo, en una de las refriegas se distinguió de una manera extraordinaria una mujer denominada Rosa Venás de Lloberas quien, después de unirse a los soldados que marchaban hacia el río Francolí, se unió a ellos en la batalla batiéndose con gran decisión y heroísmo (Moliner, 2009: 556).

Siguiendo la estela de la heroicidad demostrada por los aragoneses y catalanes, la defensa popular de Valencia resultó asimismo paradigmática. Igual que en Zaragoza o Girona, un factor fundamental en la resistencia de la ciudad fue reforzar las débiles defensas, por lo que la eficacia popular resultó esencial. Se cavaron trincheras, se fortificaron las defensas de las entradas a la ciudad y se prepararon las barricadas para frenar el paso enemigo:

"Llegó a tal extremo el entusiasmo, que hasta las mugeres mas delicadas de todas las clases y edades, olvidandose de su estado y carácter, salian á las calles, y en medio de ellas se ponian á hacer los sacos de metralla, y á desbaratar esteras para tacos; acercándose algunas hasta las mismas baterías para refrescar los cañones" (Rico, 1811: 265-266).

En ese sentido, al igual que hicieran las heroínas aragonesas, las valencianas no dudaron en ser las primeras en enfrentarse a la artillería enemiga y acudir en ayuda de los combatientes. "Fueron las primeras en arrojarse á los peligros y en crear el espíritu público. El pueblo se conmovio y las mugeres particularmente: atropellaron, maltrataron a la tropa que salió á sostener el Gobierno Francés" (Gazeta de Valencia, 17 de junio de 1808).

En los tiempos convulsos como los aquí presentados a nadie le resulta extraño que además de las voluntarias de la retaguardia, ocupadas en la atención y el cuidado de los heridos y los soldados, también hubiera mujeres que empuñaran un fusil para frenar el avance enemigo, o que en ciudades como Barcelona o Girona las mujeres corrieran al frente para atender a los soldados en el calor de la batalla. De este modo, a pesar de que la representación teórica de la feminidad -marcada por el discurso esencialista que 
relegaba al sexo femenino al universo de las emociones y de los saberes cotidianosestaba socialmente aceptada, en la práctica y en un contexto de enfrentamiento bélico se demostró poco factible y nada pragmática.

Esta circunstancia viene a confirmar la idea de que las mujeres, pese a las limitaciones que socialmente se les atribuían, en condiciones extremas las pasaron por alto debido principalmente al hecho de sentirse partícipes y comprometidas con el destino de sus conciudadanos. De manera que podemos afirmar que, tal y como se puede apreciar en los ejemplos que se han expuesto, la guerra y sus consecuencias siempre han conllevado una continua erosión de los límites establecidos entre lo masculino y lo femenino por parte de las mujeres, una remodelación y una adaptación, en suma, de los roles de género.

\section{Conclusión}

Contrariamente al silencio con el que se ha tratado la presencia femenina entre los ejércitos, ejemplos como los aquí presentados demuestran que las mujeres siempre han asistido a las tropas realizando labores tan necesarias como la intendencia, la sanidad e incluso llegando a intervenir directamente en el conflicto. Pese a su disparidad en el tiempo, todos estos ejemplos de intervención femenina tienen en común una serie de circunstancias. En primer lugar, estas actuaciones son siempre de carácter defensivo. En segundo lugar, aunque el ideal de la feminidad que se impone está perfectamente delimitado al rol de matrona, como consecuencia de la guerra, el comportamiento de las mujeres no sólo sale de los márgenes establecidos sino que es alabado siempre por los cronistas. Y en tercer lugar, la imagen que resulta de su conducta es la de mujeres que toman la apariencia de hombres y muestran un valor varonil. 


\section{BIBLIOGRAFÍA}

- Anderson, M. S. (1990): Guerra y sociedad en el Antiguo Régimen. Madrid: Ministerio de Defensa.

- Applewhite, H. B. y Levy, D. G. (eds.) (1993): Women and Politics in the Age of the Democratic Revolution, Michigan: University of Michigan.

- Arbor, A. (1992): “Women and Militant Citizenship in Revolutionary Paris". En S. E. Melzer y L. W. Kabine (eds.): Rebel Daughters: Women and the French Revolution, New York: Oxford, pp. 79-101.

- Birks, M. (ed.) (2007): The Young Hussar. The Peninsular war Journal of Colonel Thomas Wildman of Newstead Abbey. Bristol: Book Guild, pp. 24 -25.

- Black, J. (1991): A military revolution? Military change and european society, 1550-1800. London: Macmillan.

- Bowen, S. (2004): "The Real Soul of a Man in her Breast, Popular Oppression and British Nationalism in Memoirs of Female Soldiers". En Eighteenth-Century Life, n 3, pp. 20-45.

- Brett-James, A. (1972): Life in Wellington's Army. London: George Allen and Unwin, pp. 271-291.

- Carter, Th. (1860): Curiosities of War and Military Studies: Anecdotal, Descriptive and Statistical, London: Croombridge and Son's.

- Castellví, F. (1997): Narraciones históricas. Madrid: Fundación Francisco Elías de Tejada y Erasmo Pèrcopo, vol. IV.

- Clayton, E. C. (1879): Female Warriors: Memorials of Female Valour and Heroism, from the Mythological Ages to the Present Era, vol. 2. London: Tinsley Brothers Publication.

- Cook B. A. (ed.) (2006): Women and war. A Historical enciclopedia from Antiquity to the Present. Santa Bárbara, California: ABC/Clio.

- Daniel, J. E. (1820): Journal of an Officer in the Commissariat Department of the Army; comprising a narrative of the campaigning under his grace The Duke of Wellington in Portugal, Spain, France and the Netherlands, in the years 1811, 1812, 1813, 1814 and 1815, and a short account of the army of occupation in France, London: Porter and King, p.61.

- Defensa del sitio de Tortosa (1642). Madrid: Imp. Catalina de Barrio y Angulo. (Biblioteca Nacional de Madrid)

- Dekker, R. M. y Van de Pol, L. C. (1989): "Republican Heroines: Cross-Dressing Women in the French Revolutionary Armies”. En History of European Ideas, n. 3, pp. 353-63.

- De la Peña, F. (1709): Anales de Cataluña. Barcelona: Imp. Juan Pablo Martí, vol. III.

- Diario de Gerona (1809), 11 de julio: "Parte de la comandanta de la escuadra de San Narciso de la Compañía de Santa Bárbara al General Álvarez”. En (IHCM).

- Dugaw, D. (1989): "The fashion for Female Warrior Ballads: new hits and old favorites". En Warrior Women and Popular Balladry. Cambridge: University Press. 
- Ecos de la Verdad en siete diálogos sobre lo sucedido en el asedio de Barcelona, año 1706, pp. 27-28. (Biblioteca de Catalunya Ms. B-152).

- Elogio a los ilustres defensores de Zaragoza en los dos sitios de 1808 (1815). Madrid: Imprenta de Fermín Villalpando. (Biblioteca Nacional de Madrid).

- Espino, A. (2001): Guerra y Cultura en la Época Moderna. Madrid: Ministerio de Defensa.

- Fernández, E. (2009): "Las mujeres en los sitios de Girona: la Compañía de Santa Bárbara”. En I. Casrtells, G. Espigado y M.C. Romeo (coords.): Heroínas y Patriotas. Mujeres de 1808. Madrid: Cátedra, pp.105-128. Cultura. (2010): Mujeres en la Guerra de la Independencia. Madrid: Sílex y Ministerio de

- Font, J. (1897): Catalana Justícia contra les castellanes armas. Barcelona.

- Gazeta de Valencia, 17 de junio de 1808.

- Gonzalo, J. L.; Ribes, A., y Uceda, O. (1997): Els setges de Lleida, 1644-1647, Lleida: Ayuntamiento de Lleida.

- Hathaway, E. (ed.) (1997): The True Story of a Peninsular War rifleman. Swanage: Shinglepicker, pp. 250-251.

- Kaplan, T. (1990): “Conciencia Femenina y acción colectiva: el caso de Barcelona (19101918)". En J. S. Amelang y M. Nash (eds.): Historia y Género: las mujeres en la Europa Moderna y Contemporánea. Valencia: Alfons el Magnànim, pp. 267-295.

- Knighton, D. (ed.) (1838): "From W. Knighton to D. Knighton, Seville, August $23^{\text {rd }} 1809$ ". En Memoirs of Sir William Knighton, Bart. G. H. C., keeper of the privy purse during the reign of his majesty King George the Fourth, including the correspondence with many distinguished personages, in two volumes. London: Richard Bentley, vol. I, p.115.

- Lynn J. A. (2008): Women, Armies, and Warfare in Early Modern Europe. Cambridge: University Press.

- Memorial Histórico Español (1862) "Cartas de algunos padres de la compañía de Jesus sobre los sucesos de la monarquía entre los años de 1634 y 1648”. Madrid: Imp. Nacional, tom. XVI.

- Menie, M. (1893): Dowie, Women Adventurers: The Adventure Series, vol. 15, London: Unwin Bros.

- Mills, J. (1811): “From John Mills to his mother, Penamacor, August 27"th 1811 ”. En Fletcher, I. (ed.) (1995): For King and Country. The Letters and Diaries of John Mills, Coldstream Guards, 1811-1814, Staplehurst, The Spellmount Library of Military History, p. 62.

- Moliner, A. (2009): "La vida en una ciudad sitiada: Tarragona (mayo-junio de 1811)". En E. Diego (dir.): El comienzo de la Guerra de la Independencia. Madrid: Editorial Actas, pp.539-568.

- Moore Smith, G. C. (ed.) (1902): The Autobiography of Lieutenant-General Sir Harry Smith, 2 vols. London: John Murray.

- Nash, M. y Tavera, S. (eds.) (2003): Las mujeres y las guerras. El papel de las mujeres en las guerras de la Edad Antigua a la Contemporánea. Barcelona: Icaria Editorial. 
. (2002): Ciudad Roja, periodo azul. Los movimientos sociales en la Barcelona de Picasso (1888-1939). Barcelona: Península: Barcelona.

- Oman, C. (1909): "Diary of Charles Vaughan in Spain, 1808. Extract from the second Volume of the MSS, now in the Library of All Souls College", Oxford. En V.V. A. A, Publicaciones del CongresoHistórico nacional de la Guerra de la Independencia y su época (1807 -1815), Zaragoza, Tipografía de Mariano Salas, Zaragoza, 1909, Vol. I, p. 254.

- Palao, J. J. (2005): “Mujer y ejército romano durante época imperial”. En Mª C. Sevillano (ed.), El conocimiento del pasado: una herramienta para la igualdad. Salamanca: Plaza Universitaria Ediciones, pp. 169-186.

- Paret, P. (dir.) (1991): Creadores de la Estrategia Moderna. Desde Maquiavelo a la Era Nuclear. Madrid: Ministerio de Defensa.

- Prichard, T. J. (1854): The Heroines of Welsh History: Comprising Memoirs and Biographical Notices of the Celebrated Women of Wales, London: W. and F.G. Cash.

- Proesas que las barcelonesas donas han ostentat en lo siti del anny 1706 (Biblioteca de Catalunya. F. Bon. 5727).

- Rico, J. F. (1811): Memorias históricas sobre la Revolución de Valencina, que comprende desde el 23 de mayo de 1808 hasta fines del mimo año y sobre la causa criminal formada contra el P. F. Juan Rico, el Brigadier D. Vicente González, el Comisario de Guerra don Narciso Rubio y otros. Las escribe y publica el primero para inteligencia de la Nacion y de la Europa, Cádiz (Biblioteca Nacional de Madrid).

- Salmonson, J. A. (1991): The Encyclopedia of Amazons: Women Warriors from Antiquity to the Modern Era. London: Paragon House.

- Schaummann, A. L. F. (1999): On the Road with Wellington. The Diary of a War Commissary. En B. Cornwell (ed.). London: Napoleonic Library.

- Spanish's Official Papers (1808), British Library.

- Steinberg, S. (2005): La confusion des sexes: Le tranvestissement de la Renaissance à la Révoltution, Paris: Fayard.

- Stepto, M. (1996): Lieutenant Nun: Memoir of a Basque Transvestite in the New World. Boston: Beacon.

- Tone, J. L. (1999): “Spanish women in the resistance to Napoleon”. En V. L. Enders y P. B. Radcliff (eds.): Constructing Spanish Womanhood: female identity in Modern Spain. New York: State University Press, pp. 259-282.

- Verdadera y fiel relacion de todo lo sucedido en el Sitio de la ciudad de Tarragona, desde 28 de Iulio hasta 13 de Setiembre 1644 (1644). Valencia: Imp. Iuan Bautista Marçal. (Biblioteca Nacional de Madrid).

- Wheelwright, J. (1989): “Amazons and Military Maids: An Examination of Female Military Heroines in British Literature and the Changing Construction of Gender". En Women's Studies International Forum, no 5, pp. 489-502.

- Wilson, P. H. (1996): “German Women and War, 1500-1800”. En War and History, vol. 3 (2), pp. 127-160. 